\title{
REPRESENTASI WHITENESS DALAM FILM DOCTOR STRANGE
}

\author{
Feliks Hindrawan $^{1^{*}}$, Agusly $\operatorname{Irawan}^{2}$, Fanny Lesmana ${ }^{3}$ \\ ${ }^{1,2,3}$ Program Studi Ilmu Komunikasi, Fakultas Ilmu Komunikasi, Universitas Kristen Petra Surabaya \\ Jl. Siwalankerto 121 - 131, Surabaya 60236, INDONESIA \\ * Penulis korespondensi; Email: felekshindrawan@gmail.com
}

\begin{abstract}
ABSTRAK
Penelitian semiotika pada film Doctor Strange yang mengalami perubahan jalan cerita serta pemerannya dilakukan dengan pendekatan kualitatif deskriptif untuk melihat penggambaran Whiteness sebagai permasalahan yang terjadi di masyarakat Amerika. Melalui analisis menggunakan kode-kode televisi John Fiske ditemukan bahwa film Doctor Strange mengukuhkan permasalahan Whiteness terkait hegemoni kulit putih atas kulit hitam. Secara intelektual dan akademik kulit putih lebih cerdas dan logis, dalam perekonomian kulit putih lebih kaya dan makmur, secara sosial kulit putih lebih diterima, dan dalam aspek politik kulit putih berpeluang lebih akan hak kekuasaan dibanding kulit hitam.
\end{abstract}

Kata kunci: Representasi, Whiteness, Semiotika, Film.

\begin{abstract}
Semiotics research on Doctor Strange (2016) that had a change in its storyline and cast was done by using descriptive qualitative approach, in order to view the portrayal of Whiteness as a problem that happened in America society. Through an analysis using John Fiske's codes of television, it is found that Doctor Strange (2016) strenghtened the problem of Whiteness was related to hegemony of white people over black people. Doctor Strange (2016) represented that intellectually and academically, the white people were more intelligent and logical, economically richer and more prosperous, sociallymore acceptable and in the political aspect theyhadmore chance toward the right of power than the black people.
\end{abstract}

Keywords: Representation, Whiteness, Semiotic, Film.

\section{PENDAHULUAN}

Permasalahan rasialisme yang membedakan antara kulit putih dan kulit hitam menarik untuk dibahas karena permasalahan ras di Amerika sebagian besar terkonstruksi oleh hubungan mereka serta telah menjadi ciri kehidupan sehari-hari dan bersifat krusial. Permasalahan rasialisme di Amerika terjadi pada abad ke 17 dan 18 sehubungan dengan majikan kulit putih dan budak kulit hitam. Terkait untuk menghilangkan permasalahan rasialisme terhadap kulit hitam munculah civil right movement dengan tujuan mulia untuk menghapuskan permasalahan rasialisme yang terjadi di Amerika. Meskipun era tersebut telah diyakini telah berakhir dengan adanya civil right movement ternyata tidak membuat permasalahan terkait perbedaan menyangkut ketidakadilan antara kulit putih dan kulit hitam selesai. Permasalahan yang menyangkut pembedaan ini terlihat melalui aspek penghasilan, pekerjaan, tempat tinggal, kesehatan, representasi politik, dan lain-lain yang mana merupakan sebuah konsensus baru dalam ketidakadilan rasial di Amerika. (Brown, 2003). Terkait permasalahan ketidakadilan rasial maka munculah paham Whitenesss yang merupakan sebuah konstruksi sosial sebagai gaya negatif mengenai siapa yang menjadi golongan putih (Macmullan.T, 2009).
Dalam Brown (2003), Whitenesss sendiri merupakan norma umum namun tidak terlihat atau dengan kata lain keberadaannya selalu ada dan terkandung didalam kehidupan sehari-hari namun sulit untuk melihat secara langsung keadaan ini. Whitenesss dalam masyarakat Amerika tidaklah sekadar permasalahan mengenai warna kulit, melainkan penilaian siapa yang menjadi kulit putih, seperti yang dikatakan Lani Guinier dan Geral Torres bahwa Whitenesss adalah jarak sosial dari kulit hitam dan Whitenesss di Amerika secara hampir keseluruhan secara ideologi atau nilai yang dipercayai telah terkonstruksi memiliki arti "Bukan kulit Hitam".

Tidak hanya terjadi dalam kehidupan sosial bermasyarakat, permasalahan antara kulit putih dan kulit hitam teradaptasi dalam dunia perfilman yakni Hollywood. Meskipun industri perfilman Hollywood memiliki tingkat kesuksesan melebihi industri film lainnya ternyata tidak lepas dari permasalahan rasialisme yang turut ikut andil mewarnai perjalanan industri perfilman tersebut. Seperti yang dikutip melalui artikel CNN yang berjudul Chris Rock: "You're damn right Hollywood is racist" mengenai pegelaran Oscar 2016 dimana Chris Rock sebagai pembawa acara berkulit hitam melakukan canda yang diiringi dengan sindiran selama membawakan acara. Dirinya 
membahas bahwa dunia perfilman Hollywood cukup rasis sehubungan dengan keistimewaan yang diperoleh kulit putih dalam dunia perfilman Hollywood dan beragam penghargaan Oscar yang diterima (Griggs, 2016)

Menurut Foster. G.A (2003) dalam bukunya Performing Whitenesss: Post Modern Re/Construction in The Cinema bahwa sejarah dunia perfilman adalah sebuah rekam kehidupan akan adanya Whiteness. Terdapat beragam contoh film yang didapati adanya Whitenesss dalam buku Performing Whitenesss yakni Johny Weissmuller sebagai kulit putih digambarkan sebagai raja hutan dalam film Tarzan The Ape Man (1932) dengan tujuan mengaitkan mengenai tali hubungan dengan teori Darwin serta untuk menghibur para penonton Amerika karena film ini dianggap sebagai sarana fantasi masyarakat Amerika di luar kehidupan perkotaan (p.11). Charlton Heston, menjadi tawanan kera hasil dari percobaan guna mendukung evolusi dalam film the original Planet of Apes (1968) dimana Whitenesss terlihat dalam kebesaran hati seorang profesor yang diperankan Charlton Heston menerima konsekuensi untuk sepakat bergaul dengan kera serta ras lainnya, untuk mendukung evolusi atau sebuah perubahan meskipun melewati cara yang tidak mudah. Heath Ledger sebagai kesatria berkulit putih yang baik dalam film $A$ Knights Tale (2001) dimana seorang kesatria dihubungkan dengan segala hal baik dan kepiawaiannya serta menjadi kesatria selalu diasosiasikan dengan kulit putih (p.23). Mae West dan Cary Grant dalam film I'm no Angel (1933) didapati unsur Whitenesss dimana Mae West memerankan sesosok perempuan dikelilingi tiga pelayan atau budak Afrika yang juga sebagai teman berceritanya dan pemeranan sifat Mae West sendiri diceritakan diperolehnya dari para pelayannya, meskipun dirinya memerankan sosok perempuan kelas atas (p.34-36).

Selain film-film di atas menempatkan karakter kulit hitam pada posisi di bawah kulit putih atau mendapat stereotip yang berkebalikan dari kulit putih, ditemukan pula keadaan serupa dalam film superhero. Menurut Aucoin (2014), pada laman Harvard Political Review dalam artikel 'The Superhero Diversity Problem' dikatakan bahwa dalam progres dunia perfilman superhero, karakter kulit hitam selalu ditempatkan pada posisi pendukung. Karakter seperti Nick Fury dalam Avengers (2012), Perry White dalam Man of Steel (2013), dan Sam Wilson dalam Captain America Winter Soldier (2013) dimana mereka semua adalah sekelompok karakter yang penting namun mereka tidak pernah dijadikan sebagai pemimpin atau yang utama. Karakter Afrika Amerika yang paling terlihat dalam film superhero Iron Man (2010) adalah teman baik Tony Stark yakni Rhodey. Rhodey yang tertarik oleh kostum Iron Man, akhirnya dibuatkan kostum Iron Man pula oleh Tony Starks. Kisah heroik Rhodey sendiri dalam film termasuk dalam menyelamatkan Tony, dimana itu adalah hasil dari alat yang Tony buat untuknya. Sam Wilson sebagai Falcon juga memiliki kemiripan dimana menggunakan teknologi yang bukan dibuat olehnya namun serum prajurit super bekerja pada Captain America karakter, Falcon sendiri menempatkan dirinya pada produk yang dibuat oleh pemerintah. Dalam komik, karakter Afrika America pertama yakni Black Panther, membuatkan sayap tersebut bagi Falcon. Namun dalam film sayap tersebut bukan hal yang penting atau punya keterkaitan dengan kisah heroic karakter Falcon. Meskipun Rhodey dan Falcon adalah karakter yang luarbiasa, mereka tetap menjadi pendamping bagi rekan superhero kulit putih mereka (Aucoin, 2014, para.11).

Terdapat jurnal penelitian terdahulu dengan metode semiotika oleh Wiratama (2013) mahasiswa Ilmu Komunikasi Universitas Petra untuk melihat Representasi Whitenesss dalam film "Machine Gun Preacher". Sebuah film yang diangkat dari kisah nyata yang mengisahkan mengenai seorang laki-laki kulit putih yang bertobat dan ingin menebus kesalahannya dengan cara menjadi pendeta serta menolong orang kulit hitam di Afrika dalam memperjuangkan kehidupan mereka. Melalui penelitian tersebut ditemukan bahwa kedudukan kulit putih dan kulit hitam berbeda dimana kulit putih digambarkan dengan beragam hal positif dan kulit hitam digambarkan dengan beragam hal yang berkebalikan dengan kulit putih serta kulit putih dijadikan sebagai penyelamat dan pembawa perubahan bagi kulit hitam dalam film tersebut.

Jurnal penelitian yang selanjutnya dengan topik Whitenesss dilakukan oleh Nugroho (2015), mahasiswa Ilmu Komunikasi Universitas Diponegoro Semarang dengan metode penelitian semiotika menggunakan film 12 Years A Slave mengenai perjuangan kulit hitam untuk mendapatkan kebebasan dari perbudakan di Amerika yang dilakukan oleh kulit putih dan kisah tersebut diadaptasi dari kisah nyata. Didapati dari hasil penelitian tersebut bahwa kulit putih digambarkan sebagai ras yang lebih unggul dan berkuasa dibandingkan kulit hitam sebagai ras lemah dan tidak berdaya tanpa bantuan kulit putih.

Jurnal penelitian dengan topik serupa yang melibatkan antara kulit hitam dan kulit putih dilakukan oleh 
Yufandar (2016), Mahasiswa Ilmu Komunikasi dengan judul Representasi Ras Kulit Hitam dan Kulit Putih dalam film "The Avenger" dimana pada penelitian tersebut ditemukan bahwa kulit hitam dan kulit putih digambarkan memiliki kesejajaran dalam aspek kepemimpinan dan heroik, namun dalam hal sosial, ekonomi, dan intelektualitas kulit putih digambarkan lebih unggul.

Dalam penelitian kali ini peneliti menggunakan topik dan metode penelitian yang sama dengan penelitian terdahulu yakni bagaimana Whitenesss digambarkan dalam film. Subjek penelitian yang digunakan untuk melihat Representasi Whitenesss adalah film Doctor Strange yang merupakan film superhero besutan Marvel.

Film Doctor Strange adalah sebuah film yang bergenre Sci-fi, Fantasy, Adventure, dan Action besutan Marvel Cinematic Universe yang berkisah mengenai seorang dokter ahli bedah yang handal dan sombong dimana Doctor Strange atau Stephen Strange diperankan oleh Benedict Cumberbatch yang diceritakan mengalami kecelakaan sehingga mengakibatkan Stephen Strange kehilangan semua fungsi tangannya. Demi menyembuhkan kondisinya dirinya berpetualang untuk mencari obat. Ia melakukan perjalanan pencarian kesembuhan tersebut yang pada akhirnya mempertemukan dirinya dengan The Ancient One yang diperankan oleh Tilda Swinton yang kemudian pada akhirnya mengangkat Strange menjadi muridnya guna menjadi pelindung Alam Manusia dari dunia mistis atau sihir. Sebelum diangkatnya Strange menjadi murid, Mordo yang diperankan oleh aktor kulit hitam Chiwetel Ejiofor adalah murid The Ancient One yang membawa dan mempertemukan Stephen Strange kepada The Ancient One.

Marvel atau lebih dikenal Marvel entertainment, LLC merupakan perusahaan hiburan berbasis karakter paling menonjol di dunia yang dibangun di atas perpustakaan yang menghasilkan dan memiliki 8000 karakter yang ditampilkan diberbagai media lebih dari 70 tahun yang merupakan anak perusahaan The Walt Disney Company. Marvel sendiri memanfaatkan waralaba karakter dalam hiburan, perizinan dan penerbitan (About Marvel: Corporate Information, n.d.)

Film Doctor Strange mengalami beragam perubahan baik pada tokoh dan jalan ceritanya. Melalui laman www.looper.com dalam artikel "How Doctor Strange is different in the comics" bahwa banyak hal yang berbeda dari cerita pada komiknya yakni The Ancient One yang berbeda sekali dari karakter aslinya. Per- bedaan asal muasal Baron Mordo yang seharusnya adalah musuh utama Doctor Strange dalam komik namun dalam film dirinya hanya sebagai murid The Ancient One yang dan Kaecilius seorang penjahat yang seharusnya dalam komik adalah seorang asisten Baron Mordo namun dalam layar lebar dirinya bagai musuh utama yang berusaha akan dikalahkan dan beberapa perbedaan lainnya (Snellgrove, 2016, para. $2,8,16,17)$.

Desta (2016) melalui laman Vanity Fair mengenai film Doctor Strange dalam artikelnya dibahas mengenai beragam hal mengapa karakter asli The Ancient One atau karakter pendukung pemeran utama dalam film Doctor Strange berbeda dengan komik atau dengan kata lain dalam film layar lebar The Ancient One diperankan oleh seorang kulit putih dan hal tersebut menuai beragam kontroversi baik dari para fans maupun jawaban para produser dan directornya yang memberikan berbagai alasan sehubungan dengan hal tersebut. Dikutip pula melalui laman Vulture yang ditulis bahwa karakter yang seharusnya berkulit putih juga digantikan oleh seorang aktor kulit hitam yakni Ejiofor atau dikenal Chiwetel Ejiofor (Buchanan, 2016, para.3).

Melalui fenomena dan perubahan tokoh serta jalan cerita pada film Doctor Strange, peneliti ingin melakukan penelitian untuk melihat bagaimana Whitenesss direpresentasikan dalam film Doctor Strange yang mana merupakan film produksi Hollywood dan terdistribusikan ke seluruh dunia termasuk Indonesia. Penting adanya untuk dilakukan penelitian terkait representasi Whitenesss dalam media massa film karena di Indonesia sendiri permasalahan rasialisme kuat sekali diberitakan di media massa mengenai permasalahan di Indonesia terkait siapa menjadi pribumi dan bukan pribumi. Dikutip melalui laman CNN Indonesia bahkan perdebatan permasalahan pribumi dan non pribumi di Indonesia ditanggapi serius oleh Wiranto selaku Menteri Koordinator Politik Hukum dan HAM di Indonesia. Dirinya mengatakan bahwa "jika dua istilah (pribumi dan non pribumi) itu terus didengungkan maka berpotensi menghambat persatuan Indonesia" yang mana menjelaskan bahwa permasalahan rasialisme terkait mengakui bahkan mengakuisisi aspek-aspek dalam kehidupan sosial juga terjadi di Indonesia (Pratama, 2017, para.1).

Dalam penelitian kali ini peneliti menggunakan metode penelitian semiotika. Menurut Wibowo. I.S.W (2013), representasi adalah suatu hal yang bekerja pada hubungan tanda dan makna atau dengan kata 
lain representasi adalah sebuah bentuk usaha kontruksi yang sifatnya dinamis dan terus berkembang seiring dengan kemampuan intelektual dan kebutuhan dari para pengguna tanda yakni manusia itu sendiri yang terus berubah. Dimana representasi dianggap tepat sebagai sarana untuk melihat tanda dan makna sehubungan dengan permasalahan Whitenesss yang sifatnya tidak terlihat.

\section{TINJAUAN PUSTAKA}

\subsection{Whiteness}

Kulit hitam dan kulit putih merupakan bagian dari permasalahan ras di Amerika. Sejarah mencatat bahwa permasalahan rasialisme ini membahas mengenai perbedaan hak yang diperoleh antara kulit putih dan kulit hitam di masyarakat, namun permasalahan ini sempat menemukan titik terang ketika muncul sebuah gerakan civil right movement dengan tujuan untuk menghapuskan ketidakadilan yang dialami sehubungan dengan perbedaan ras. Gerakan ini sempat menuai improvisasi positif terhadap permasalahan rasialisme yang terjadi. Karena begitu kompleksnya permasalahan rasialisme yang sudah mengakar ternyata ditemukan permasalahan baru terkait ras yang mana terlihat melalui ketidakadilan dalam aspek penghasilan, pekerjaan, tempat tinggal, kesehatan, representasi politik, dan lain-lain yang mana merupakan sebuah konsensus baru dalam ketidakadilan rasial di Amerika dimana memunculkan paham Whitenesss. (Brown, M.K, 2003).

Whitenesss sendiri adalah sebuah permasalahan rasialisme yang mana menguntukan ras kulit putih dalam hal perlakuan dan keuntungan yang diperoleh seperti pada bidang sosial, politik, ekonomi. Permasalahan ini telah meresap menjadi sebuah nilai dan norma yang sudah dianggap normal oleh masyarakat Amerika yakni kulit putih itu sendiri. Dalam setiap keputusan yang dibentuk oleh kulit putih Amerika sering dipengaruhi dan dibentuk oleh faktor hubungan antara Whitenesss dan akumulasi keuntungan ras. Investasi posesif dalam Whitenesss ibaratkan sebuah properti, seperti yang disampaikan oleh Cheryl Harris bahwa penolakan terhadap kesempatan komunitas kulit berwarna atau kesempatan untuk mengakumulasi aset. Pada kenyataannya bahwa kulit putih mendapat hak legal untuk mengesampingkan yang lain mengenai keuntungan yang melekat dalam Whitenesss dimana mereka telah mengakumulasi kemakmuran, kekuasaan dan kesempatan dengan cara mengorbankan seseorang yang memang terlahir bukan kulit putih. Keuntungan kulit putih ini sifatnya telah melekat dan kebanyakan mengenai ketidakseim- bangan sebuah komunitas ras fokus pada jual beli tenaga kerja, sistem keadilan kriminalitas, pemisahan tempat tinggal, dan pendidikan. Whitenesss di Amerika tidak sesederhana permasalahan kulit melainkan siapa yang menjadi kulit putih, dimana ditekankan lagi oleh Lani Guinier dan Geral Torres bahwa Whitenesss merupakan jarak sosial dari kulit hitam, dengan kata lain bahwa Whitenesss di Amerika sebagian besar atau potongan besarnya adalah 'bukan hitam' (Brown, M.K (2003).

The Thernstroms menekankan bahwa kulit putih tidak terlihat secara rasial tidak terlihat karena mereka memiliki segala kekuatan, tetapi mereka tidak merekomendasikan untuk memberikan kekuasaan kepada kulit hitam dalam rangka menyeimbangkan ketidak terlihatan ras. (dalam Brown, M.K, p.64, 2003).

Dalam Brown (2003) ditambahkan bahwa menghilangkan keuntungan kulit putih tidak pernah dianggap, melainkan mereka mengusulkan dalam rangka membuat ras dapat sedikit terlihat yakni dengan cara mendistribusikan ulang kekuatan putih, dengan mendiversivikasikan kekuatan dominan kuit putih, yakni:

- Politik: terkait kekuasaan yang dimiliki dan diperoleh.

- Sosial: terkait penerimaan seseorang dimasyarakat

- Intelektual: sehubungan dengan seseorang yang terpelajar.

- Akademik: sehubungan dengan kecerdasannya.

- Ekonomi: sehubungan dengan kemakmuran materi yang dimilikinya.

\subsection{Representasi}

Representasi merupakan kegunaan dari tanda. Marcel Danesi mendefinisikannya sebagai berikut: "proses merekam ide, pengetahuan, atau pesan dalam beberapa cara fisik disebut representasi. Ini dapat didefinisikan lebih tepat sebagai kegunaan dari tanda yaitu untuk menyambungkan, melukiskan, meniru sesuatu yang dirasa, dimengerti, diimajinasikan atau dirasakan dalam beberapa bentuk fisik.

\subsection{Semiotika}

Menurut Wibowo, I.S.W. (2013), semiotika adalah studi terhadap pengkajian tanda-tanda atau kode-kode yakni sistem apapun yang memungkinkan kita memandang entitas-entitas sebagai sesuatu yang bisa dimaknai atau memiliki warna. Secara estimologis semiotika berasal dari kata Yunani Semeion yang 
artinya adalah tanda. Dimana tanda itu dapat didefinisikan sebagai suatu yang atas dasar konvensi sosial yang terbangun sebelumnya atau mewakili sesuatu yang lain dimana tanda selalu diasosiasikan merujuk pada hal lainnya. Analisis semiotika sendiri digunakan untuk mengetahui sesuatu hal yang aneh dan memunculkan pertanyaan lebih lanjut ketika kita membaca sebuah teks atau menemukan suatu hal tersembunyi terhadap sebuah teks. Tanda itu sendiri merupakan cerminan dari realitas yang dikonstruksikan lewat kata-kata.

\subsection{Kode Televisi John Fiske}

Menurut Fiske, p.4, (1987), Terdapat 3 pengkodean televisi.

1. Level Pertama: Reality atau Realita:Penampilan atau appearance, Dress atau busana, Make Up, Behavior atau Perilaku, Gaya bicara,Ekspresi, Sikap Gerak

2. Level kedua: Representation atau Representasi: Camera, Lighting, Editing, Musik, Sound

Yang kemudian ditransmisikan ke kode representasi konvensional yang membentuk representasi seperti: Narrative, Conflict atau konflik, Karakter, Action, Dialogue atau percakapan, Setting, Casting

3. Level ketiga: Ideology atau Ideologi yang diorganisasikan kedalam koherensi dan penerimaan sosial dengan kode ideologi seperti individualism, patriarki, ras, kelas, materialism, kapitalisme.

\section{METODE}

\subsection{Konseptualisasi Penelitian}

Dalam melakukan penelitian terkait representasi whiteness dalam film Doctor Strange peneliti menggunakan metode semiotika yang merupakan studi untuk mengkaji tanda-tanda atau kode-kode yakni sistem apapun yang memungkinkan kita memandang entitas-entitas sebagai sesuatu yang bisa dimaknai (Wibowo, I.S.W. 2013). Dalam menganalisis representasi whiteness pada penelitian ini menggunakan teori kode-kode televisi John Fiske yang mencakup level realita, representasi, dan ideologi.

\subsubsection{Subjek Penelitian}

Subjek penelitian yang digunakan terkait bagaimana Whiteness sebagai permasalahan rasialisme antara kulit putih dan kulit hitam terkait hak yang diperoleh direpresentasikan adalah film Doctor Strange.

\subsubsection{Analisis Data}

Peneliti mengumpulkan potongan adegan yang mengindikasikan permasalahan whiteness dalam film Doctor Strange yang dianalisis dengan kode-kode televise John Fiske dimana terdapat tiga level yakni realita, representasi, dan ideologi. Setelah melakukan analisa, maka akan dilakukan intepretasi data yang diakhiri dengan menyimpulkan baik temuan, analisis, dan intepretasi data mengenai bagaimana whiteness direpresentasikan

\subsection{Temuan Data}

Dalam film Doctor Strange peneliti menemukan bahwa kulit putih mendominasi dalam aspek intelektual, akademik, ekonomi, sosial, dan politik. Dalam film Doctor Strange kulit putih digambarkan lebih cerdas, logis, kaya, makmur, secara sosial lebih diterima, dan berpeluang lebih akan hak kekuasaan daripada kulit.

\subsection{Analisis dan Interpretasi}

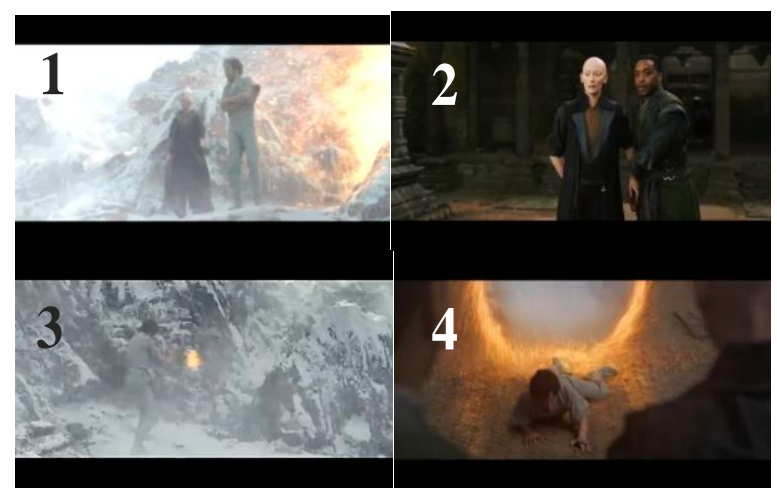

Gambar 1, The Ancient One memberikan ujian pelatihan Stephen Strange (Sumber: Film Doctor Strange 2016)

Kulit putih digambarkan sebagai sosok yang cerdas melalui penguasaannya dalam sebuah ilmu baru dan tantangan baru dan kulit hitam adalah sosok yang pesimis dan tidak berkemampuan seperti kulit putih.. Scene ini bercerita bagaimana The Ancient One memeberikan pelatihan pada Stephen Strange dengan dibawanya ke sebuah gunung bersalju dan Baron Mordo terkaget akan pelatihan yang diberikan oleh The Ancient One kepada Stephen Strange. Pada level realita terlihat gesture, ekspresi dan lingkungan. Pada aspek ekspresi The Ancient One dan Baron Mordo terlihat tatapan matanya ditekan oleh dahi kepalanya dengan mulut sedikit terbuka seperti rahang yang kaku seperti sedang pada tensi yang tinggi atau keadaan yang bertensi tinggi. Pada aspek gesture Stephen Strange terlihat sedang berdiri memeluk dirinya sendiri seperti kedinginan dan tersungkur jatuh kebawah pada shot keempat, sedangkan Baron Mordo melangkahkan kaki sedikit kedepan dan memegang samping tubuh The Ancient One untuk melakukan sebuah tindakan atau langkah, dan The Ancient One sendiri berdiri dengan tangan berada di 
belakang seperti sedang tidak ingin atau membatasi untuk tidak melakukan kontak dengan orang lain atau menjauh dari sesuatu (Navarro \& Karlins, 2008). Aspek lingkungan di tempat ini terlihat bersalju dan dingin.

Pada level representasi dilihat melalui aspek kamera, setting/ latar dan dialog. Dalam aspek kamera peneliti melihat dari 4 shot yakni shot pertama dan ketiga diambil menggunakan longshot untuk memperlihatkan detil mengenai hubungan antara keadaan lingkungan sekitar dimana sosok atau orang dalam gambar itu berada. Shot kedua diambil menggunakan medium shot untuk memperlihatkan detil gesture dari The Ancient One dan Baron Mordo mengetahui bahwa Stephen Strange diberikan pelatihan seperti itu, dan shot keempat diambil menggunakan Medium close up memperlihatkan detil Stephen Strange berhasil dalam menyelesaikan latihan atau tes yang diberikan dimana selain itu membantu kita memberikan penilaian terhadap subjek yang masuk pada gambar. Setting dalam scene ini berada pada Gunung bersalju. Pada aspek dialog akan muncul seperti ini perbincangan yang dilakukan oleh Baron Mordo dan The Ancient One:

The Ancient One: But you will likely go into shock within the first 2 minutes.

Tapi, kamu akan masuk dalam keadaan terkejut setelah 2 menit pertama

Stephen Strange: What? Apa?

The Ancient One: Surrender, Stephen. Berserahlah Stephen

Stephen Strange: No, no!!! Don't!

Tidak, Tidak!!! Jangan!

Baron Mordo: How is our new recruit?

Bagaimana rekrutan baru kita?

The Ancient One: We shall see, Any second now.

Kita lihat saja, beberapa detik lagi

Baron Mordo: No, not again.

Maybe I should...

Tidak, tidak lagi

Mungkin aku harus.....

Terlihat dari dialog bahwa Baron Mordo kuatir akan latihan yang diberikan The Ancient One terhadap Stephen Strange digunung bersalju dan latihan ini bukanlah yang pertama kali dilakukan oleh The Ancient One kepada muridnya dan seperti terkesan yang dahulu memiliki memori kurang baik.

Setting dalam Scene ini adalah di gunung bersalju dimana sehubungan dengan naik kepuncak gunung, ada sebuah kegiatan yang dinamakan "Expedition Denali"

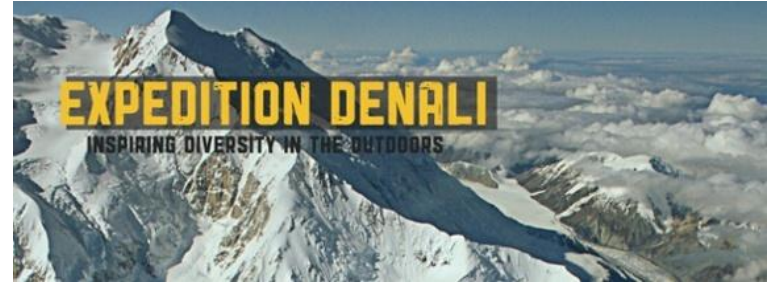

Gambar 2. Expedition Denali

(Sumber: (https://expeditiondenali.nols.edu/home)

Expedition Denali merupakan sebuah kegiatan outdoor yang terdiri dari kulit hitam dan perempuan untuk mendaki gunung Denali dengan tinggi 20,328 kaki, dimana memiliki slogan "Inspiring Diversity in the outdoors" dimana membawa sebuah nilai untuk menginspirasi kaum kulit berwarna yakni African American atau kulit hitam untuk dapat menjadikan kegiatan pendakian sebagai hal yang memang tidak diperuntukkan untuk satu ras atau kaum saja.

Dalam artikel "All African-American Team Takes on Denali - Why It Matters" yang ditulis oleh Mils (2013), terdapat kutipan menarik sehubungan dengan Expedisi Denali dan ragam permasalahan yang diangkat dalam program tersebut: "And for a variety of different social and cultural reasons the world of mountaineering has been relegated almost exclusively to white men. Without any deliberate effort to prevent blacks and other minorities from becoming involved in the sport, the number non-white participants is conspicuously low. The organizers of Expedition Denali merely hope to change that by introducing a new narrative into the mix and perhaps redefine what it means to be a climber." (http://adventureblog.nationalgeographic.com/2013/05/09/first-all-african-american-team-takes-on-denali-in-june-why-it-matters/)

Terlihat bahwa melalui variasi pengambilan gambar, ekspresi, dan gesture serta setting dan dialog bahwa kulit putih digambarkan memiliki kemampuan yang lebih baik dan tingkat kepercayaan diri lebih daripada kulit hitam dimana ditunjukkan melalui Stephen Strange yang berhasil melampaui pelatihan dari The Ancient One yang pada awalnya dirinya terlihat berusaha untuk tenang dari ekspresinya namun gesturenya menunjukkan penghindaran akan sesuatu dan Baron Mordo yang sempat khawatir melihat kejadian ini berulang kembali. Namun terlihat Stephen Strange (kulit putih) berhasil menyelesaikan hal yang baru pertama kali dan memiliki risiko.

\subsection{Kulit putih lebih cerdas dan logis dibanding- kan kulit hitam}

Kulit putih digambarkan sebagai sosok yang erat kaitannya dengan ilmu pengetahuan dan digambarkan memiliki kemampuan cepat dalam belajar sesuatu 
yang baru dan segala pernyataan yang terucap didasarkan melalui fakta yang logis. Hal tersebut digambarkan melalui bagaimana kulit putih memperlakukan buku yang berisi ilmu pengetahuan selalu digunakan untuk melancarkan tujuannya dan memiliki ambisi untuk menguasai ilmu baru.

Kulit hitam digambarkan mudah tersinggung, tidak berpikir secara logis, dan kekurangan ide serta gagasan karena dalam setiap penyampaiannya selalu didasari oleh emosi pribadi. Maka kulit putih yang selalu diasosiasikan dengan kecerdasan dan segala kehebatannya dalam berperilaku dalam melakukan segala sesuatu. Kulit hitam mendapatkan diskriminasi bahwa mereka secara intelektual dan akademik seperti pendidikan tidak setara dengan kulit putih karena emosinya yang mendasari segala tindakannya. Menurut Brown (2003), dikatakan bahwa dalam kulit hitam dipandang tidak memiliki kecerdasan setara dengan kulit putih.

\subsection{Kulit putih lebih kaya dan makmur diban- ding kulit hitam}

Kulit putih digambarkan memiliki tingkat kemakmuran yang baik dan hal tersebut ditunjukkan jelas melalui kendaraannya. Doctor Stephen Strange (kulit putih) digambarkan menggunakan Lamborghini Huracan yang memiliki harga sekitar Rp.2.500.000. 000 atau sekitar 200.000 dollar Amerika dan Rumah The Ancient One (kulit putih) yang besar dengan dilayani Baron Mordo (kulit hitam). Kulit hitam identik dengan kemakmuran rendah dibandingkan kulit putih serta menjadi asisten kulit putih bahkan identik tempat tinggal yang selalu pada posisi lingkungan kemiskinan.

Menurut Badger (2015, para.2) terdapat sebuah kutipan menarik mengenai penelitian mengenai kemiskinan yang dihadapi antara kulit putih dan kulit hitam. Dalam lima tahun pada data Komunitas Survey Amerika dari 2009-2013, lebih dari 3 orang miskin Afrika Amerika di Chicago tinggal dalam tingkat kemiskinn yang tinggi (dengan tingkat kemiskinan lebih dari 40\%). Angka tersebut semakin memburuk sejak tahun 2000 dan hal ini adalah sepuluh kali lebih tinggi dari kulit putih Amerika yang juga mengalami kemiskinan.

Sehingga kulit putih dan kulit hitam akan kerat kaitannya memiliki tingkat kemakmuran atau kekayaan yang berbeda. Kulit putih akan selalu ada di atas kulit hitam bahkan dalam status kemiskinan sekalipun. Dalam film Doctor Strange kulit putih digambarkan memiliki latar belakang dengan tingkat kemakmuran tinggi namun kulit hitam digambarkan identik dengan lingkungan jalanan yang diasosiasikan dengan wilayah tertinggal.

\subsection{Kulit putih secara sosial lebih diterima di- banding kulit hitam}

Kulit putih di dalam film Doctor Strange digambarkan erat hubungannya dengan dunia medis atau rumah sakit. Keterlihatan tersebut diperjelas dengan scene ketika The Ancient One (kulit putih) dan Stephen Strange (kulit putih) mengalami kecelakaan secara spontan dibawa ke rumah sakit sedangkan tidak nampak Baron Mordo (kulit hitam) muncul pada setting/ lokasi rumah sakit. Mudahnya akses kesehatan baik dalam penerimaan dan perawatan yang diperoleh kulit putih, menyebabkan mereka akan cenderung menjadikan rumah sakit atau institusi medis sebagai rujukan secara spontan jika mengalami permasalahan yang membutuhkan perawatan medis. Kulit hitam menurut Brown (2003), tidak mendapatkan pelayanan dan penerimaan sebaik kulit putih dalam institusi medis.

Dikutip pula melalui laman BBC menurut Vaidyanathan (2016), bahwa kulit hitam cenderung akan tinggal di lingkungan yang kumuh dimana hal ini bukan sekedar permasalahan mengenai pilihan ataupun kesempatan mereka melainkan ada unsur perencanaan untuk membuat masyarakat Afrika Amerika tinggal pada area tertentu. (www.bbc.com/news/ world-us-canada-35255835). Bahkan dalam Brown (2003), kulit putih akan cenderung meninggalkan tempat tinggalnya jika ada kulit hitam yang hadir dilokasi tempat tinggal tersebut dibandingkan jika Asia atau latinos yang hadir kedalam lingkungan tempat tinggal tersebut. Bahkan kelompok ras atau etnik baru yang datang, secara sejarah terintegrasi dijanjikan tidak akan diperlakukan seperti kulit hitam. Terkait dalam aspek institusi sosial, kulit hitam sebagai ras mengalami penolakan serta dianggap berbeda. Brown (2003), menambahkan bahwa dalam pelayanan medis, kulit hitam akan cenderung tidak memperoleh perlakuan sama sebaik kulit putih.

Diperlihatkan melalui akses yang baik akan pelayanan medis ataupun wilayah serta lingkungan tempat tinggal terlihat adanya jarak dan penerimaan berbeda antara kulit putih dan kulit sehingga pada film Doctor Strange kulit putih digambarkan memiliki penerimaan yang baik dibandingkan kulit hitam secara sosial.

\subsection{Kulit putih berpeluang lebih akan hak keku- asaan dibanding kulit hitam}

Stephen Strange (kulit putih) mendapatkan hak akan kekuasaan lebih istimewa. Kekuasaan yang lebih istimewa dibandingkan kulit hitam ditunjukkan bahwa Stephen Strange (kulit putih) mendapatkan 
hak sebagai Master Strange di New York Sanctum yang merupakan sebuah tempat penting dalam film serta menerima mandat penting dari The Ancient One (kulit putih) mengenai bagaimana menghadapi permasalahan kedepannya tanpa ada kulit hitam di lokasi tersebut. Sehingga kulit hitam cenderung tidak mendapatkan hak bahkan jabatan setinggi kulit putih dan posisinya hanya sebatas rekan atau pendamping saja. Aspek politik kulit putih mendominasi dalam kekuasaannya di pemerintahan dan hal ini terkait kekuasaan yang dimiliki oleh kulit putih. Menurut Brown (2003), bahwa permasalahan rasialisme terkait pemilihan kursi di pemerintahan tetap terkandung dalam dunia pemerintahan dimana kulit putih akan cenderung memilih kulit putih dibandingkan kulit hitam. Dimana ada sebuah kutipan menarik yakni "another study found that even when all voters have similar evaluations of city services, white voters express far greater disapproval of a black mayor than do black voters" (p.209).

Dari pernyataan diatas dikukuhkan bahwa kekuasaan dipengaruhi oleh permasalahan rasialisme dimana ditunjukkan bahwa kulit putih cenderung lebih mudah menolak kulit hitam sebagai walikota dibandingkan yang dilakukan pemilih kulit hitam. Permasalahan rasialisme terlihat bahwa kulit putih dengan jelas tidak akan memilih dan mempercayai kulit hitam sebagai pemimpin. Hal ini sangat jelas digambarkan dalam film Doctor Strange dalam aspek politik terkait kekuasaan kulit putih akan diberikan ke sesama kulit putih dibandingkan kulit hitam.

\section{SIMPULAN}

Melalui penelitian ini dapat disimpulkan bahwa film Doctor Strange mengukuhkan permasalahan Whitenesss mengenai Hegemoni kulit putih atas kulit hitam terkait keuntungan ras kulit putih yang terjadi di masyarakat Amerika dalam aspek intelektual, akademik, ekonomi, sosial, dan politik.

Penelitian ke depannya dapat dilakukan dengan metode penelitian yang sama, namun mengangkat permasalahan Orientalisme dalam film Doctor Strange karena terlihat secara tidak langsung banyak aspek-aspek yang berlatarbelakang Asia muncul dalam film Doctor Strange seperti penguasaan ilmu mistis oleh kulit putih yang seharusnya merupakan latar belakang Asia di dalam film Doctor Strange.

\section{DAFTAR PUSTAKA}

Aucoin, J. (2014). The Superhero Diversity Problem. Retrieved March 11, 2017, from www.harvardpolitics.com/books-arts/superhero-diversityproblem

About Marvel: Corporate Information. (n.d.). Retrieved February 17, 2017, fromhttp://www.marvel. com/corporate/about

Brown, M.K, et al. (2003). Whitewashing Race: The Myth of a Color Blind Society. Berkeley: University of California

Desta, Yohana (2016). Doctor StrangeDirector Explains Why The Ancient One Was Never Going to Be Asian in the Movie. Retrieved February 15, 2017, fromhttp://www.vanityfair.com/Hollywood/2016/10/doctor-strange-ancient-onedirector

Fiske, J. (1987). Television Culture. London: Routledge.

Foster, G.A. (2003). Performing Whitenesss: Post Modern Re/Constructions in the Cinema. New York: State University of New York Press

Macmullan, T. (2009). Habits of Whitenesss. Indiana: Indiana University Press

Navarro, Joe \& Karlins, Marvin. (2008). What Every Body Is Saying: An Ex-FBI Agents Guide to Speed Reading People. New York: Collins.

NOLS. (n.d.). Expedition Denali: Inspiring Diversity in the Outdoors. Retrieved May 20, 2017, from https://expeditiondenali.nols.edu/home

Nugroho, A.A. (2015). Jurnal: Representasi Whitenesss dalam film 12 Years A Slave. Semarang: Portal Garuda.

Pratama, A.B. (2017). Wiranto Tak Setuju Istilah Pribumi dan Non Pribumi. Retrieved April 4, 2017, from http://www.cnnindonesia.com/nasional/20170126 160557-20-189277/wiranto-taksetuju-istilah-pribumi-dan-non-pribumi/

Vaidyanathan, R. (2016). Why don't Black and white Americans live together?. Retreieved May 23, 2017, from www.bbc.com/news/world-us-canada-35255835

Wibowo, I.S.W. (2013). Semiotika Komunikasi: Aplikasi Praktis Bagi Penelitian dan Skripsi Komunikasi. Jakarta: Penerbit Mitra Wacana Media

Wiratama, D. (2013). Jurnal: Representasi Whitenesss dalam film Machine Gun Preacher. Surabaya: UK Petra.

Yufandar, B.T. (2016). Jurnal: Representasi Kulit Hitam dan Kulit Puth dalam film "The Avengers" Surabaya: UK Petra. 